\title{
OUTCOME OF VARIOUS SURGICAL PROCEDURES AND THEIR OUTCOME FOLLOWING ENTERIC PERFORATION AT DR. RUTH KM PFAU, CIVIL HOSPITAL, KARACHI.
}

\footnotetext{
1. MBBS, FCPS, MRCS

Senior Women Medical Officer Dr.Ruth KM Pfau, Civil Hospital Karachi.

2. MBBS, FCPS

Senior Medical Officer

Dr. Ruth KM Pfau, Civil Hospital Karachi.

3. MBBS, FCPS

Senior Registrar

Sir Syed College of Medical

Sciences for Girls Karachi.

4. MBBS, FRCS (Ireland)

Professor of Surgery

Dow University of Health Sciences

Civil Hospital Karachi.
}

Correspondence Address:

Dr. Paras Mahesh

Surgical Unit: I, Dr. Ruth Pfau,

Civil Hospital, Karachi.

doc.paras82@gmail.com

Article received on:

14/12/2018

Accepted for publication:

$15 / 03 / 2019$

Received after proof reading:

30/09/2019

\section{INTRODUCTION}

Typhoid fever caused by Salmonella typhi, gram negative bacteria, transmitted by faecooral route. ${ }^{1}$ It infects around 21.6 million people worldwide with an incidence of 3.6 per 1,000 population. The expected mortality because of typhoid fever is 200,000 people every year. Nearly $80 \%$ of its victims belong to South Asian countries like India, Bangladesh, Pakistan, China, Indonesia, and Nepal. ${ }^{2}$ Its high contribution from the developing world correlates with miserable socioeconomic circumstances, overpopulation, lack of clean drinking water and deprived hygienic conditions. ${ }^{3}$ Uncomplicated typhoid fever treated conservatively with antibiotic has a mortality rate is less than one percent. ${ }^{2}$ If left untreated, can result in life threatening complications amongst which perforation with peritonitis (1-3\%), gastrointestinal bleeding (10-20\%) commonly present during the second or third week of illness, secondary to necrosis of Peyer's patches at terminal ileum. ${ }^{4,5}$ Frequently, untreated typhoid fever has a mortality rate of around $10 \%-20 \%{ }^{2}$ Surgery is the treatment of choice in typhoid peritonitis. Various surgical options are primary repair of the perforation, simple repair with proximal ileostomy, resection of disease segment and anastomosis, exteriorization of perforation as loop ileostomy, bypass the perforation as ileotransverse anastomosis, resection of perforated segment followed by exteriorization of both ends of affected bowel. ${ }^{1,4,6,7,8}$ The prognosis in patients suffering with typhoid fever depends primarily on the rapid diagnosis and beginning of effective treatment. This is the reason, surgical outcome is strongly influenced by either because of delay in diagnosis, delay in referral to tertiary care center or prolonged postponement of surgery, which eventually increases the percentage of morbidity and mortality. Surgery in this regard required to select the appropriate procedure according to the clinical presentation and operative findings 
for any patient. ${ }^{3}$

The object of this study is to observe various surgical procedures and their outcome in patients presenting with peritonitis, secondary to typhoid perforation.

\section{METHODS}

This prospective, observational study was conducted in surgical unit: V, Dr. Ruth K.M.Pfau, Civil Hospital, Karachi, over a period of 37 months from December 2014 to December 2017. A total of 25 operated cases of patients presenting with history of fever and abdominal pain followed by clinical diagnosis of peritonitis, were included in the study by simple consecutive sampling technique. Patients suffering from chronic infectious conditions like tuberculosis, malignancy, traumatic perforation, patients on steroid and those operated at other center then referred to our center were excluded from the study. Informed consent was obtained from all the patients included in the study.

The clinical diagnosis of peritonitis was made on history of fever followed with abdominal pain, abdominal distension, tenderness, guarding or rigidity, supported with pneumoperitoneum on plain erect chest radiography, and on operative finding of terminal ileal perforation. During preoperative resuscitation all patients received intravenous third generation cephalosporin with metronidazole, nasogastric tube, urethral catherization, then shifted to emergency operation theatre for laparotomy under general anesthesia. The decision of surgical treatment option for ileal perforation was taken at surgeon's discretion according to case to case operative findings. In all cases peritoneal cavity was thoroughly washed with copious amount of warm normal saline and drain placed in pelvis. Abdomen was closed either by en masse with prolene no.1. Whoever, in severely contaminated cases deep tension suture technique with prolene no. 1, was used to close the abdomen. Skin was closed with interrupted prolene $2 / 0$ sutures and in particularly contaminated cases skin was left open.

Post-operatively patients were kept nil per orally with nasogastric tubes till return of bowl sounds or no stoma output in patients where stoma was formed. On the other hand, patients in which primary repair was done kept nil per orally for a period of four days followed by liquids then solids. Diagnostic confirmation of typhoid ileal perforation was made on histopathological analysis of biopsy from the edge of ileal perforation. Patients were discharged for weekly follow up for one month, with subsequent follow up was continued on monthly basis for next two months. Patients requiring reversal of stoma were than readmitted at the end of three months. Following reversal of stoma same protocol of follow up was observed as mentioned above for primary surgery. All data including demographic details like age, sex, along with supportive investigations for peritonitis ( $\mathrm{x}$-ray chest, erect/ supine plain x-ray abdominal film, complete blood picture, etc.), operative findings, procedure performed, morbidity, mortality and total duration of hospital stay were recorded through a proforma. The data was analyzed using Statistical Package for Social Sciences (SPSS) version 15. Descriptive statistics like frequency, percentage, mean etc. were calculated.

\section{RESULTS}

During thirty-seven months' period 25 patients were admitted with the clinical diagnosis of typhoid ileal perforation. The study showed a male predominance with 19 males and 6 females, with male/female ratio was 3:1. Table-I The mean age was of $29.52 \pm 15$ standard deviation (SD) years. Table-Il The fever followed by abdominal pain were the commonest symptoms, with the mean duration for febrile illness and abdominal pain were 7 and 5 days. Table-III Majority of the patients presented 24 hours after the development of peritonitis. Generalized peritonitis was found in $23(92 \%)$ of patients. The most common operative finding was solitary perforation in the terminal ileum in $23(92 \%)$ cases, whereas multiple perforations were found in 2(8\%) patients. Table-IV The mean distance of perforation from ileo-caecal junction was $41.32 \pm 25.6 \mathrm{SD}$. Loop ileostomy was the commonest procedure performed $14(56 \%)$ of patients. En masse abdominal wall closure was performed in 22(88\%), however, skin was closed in only $11(44 \%)$. Wound infection was common 
complication noted but unfortunately 2(8\%) patients died during treatment. (Table-V)

\begin{tabular}{c|c} 
Male & $19(76 \%)$ \\
\hline Female & $06(24 \%)$
\end{tabular}

Table-I. Gender distribution

\begin{tabular}{|c|c|}
\hline $\begin{array}{c}\text { Age groups(Years) } \\
\text { Mean } \pm \text { SD: } 29.52 \pm 15\end{array}$ & $\begin{array}{l}\text { Number of patients } \\
\text { (Percentage) }\end{array}$ \\
\hline $13-20$ years & $10(40 \%)$ \\
\hline $21-30$ years & $8(32 \%)$ \\
\hline $31-40$ years & $2(8 \%)$ \\
\hline $41-50$ years & $2(8 \%)$ \\
\hline $51-60$ years & $2(8 \%)$ \\
\hline Equal to \& greater than 70 years & $1(4 \%)$ \\
\hline \multicolumn{2}{|c|}{ Table-II. Age distribution } \\
\hline \multirow[b]{2}{*}{$\begin{array}{l}\text { Likely duration of peritonitis at } \\
\text { Presentation in terms of hours }\end{array}$} & Within 24 hours:09 \\
\hline & $\begin{array}{l}\text { More than } 24 \\
\text { hours: } 16\end{array}$ \\
\hline \multicolumn{2}{|l|}{ Abdominal Symptoms } \\
\hline Fever & $25(100 \%)$ \\
\hline Abdominal pain & $25(100 \%)$ \\
\hline Vomiting & $17(68 \%)$ \\
\hline Absolute / relative constipation & $17(68 \%)$ \\
\hline Abdominal distension & $13(52 \%)$ \\
\hline Diarrhea & $6(24 \%)$ \\
\hline Nausea & $3(12 \%)$ \\
\hline \multirow{2}{*}{ Duration of fever in days } & Mean \pm SD: $7.08 \pm 2$ \\
\hline & Median: 7 \\
\hline \multirow{2}{*}{$\begin{array}{l}\text { Duration of abdominal pain in } \\
\text { days }\end{array}$} & Mean \pm SD:5.04 \pm 5.51 \\
\hline & Median:3 \\
\hline \multirow{2}{*}{$\begin{array}{l}\text { Clinical presentation of } \\
\text { peritonitis }\end{array}$} & Generalized: 23(92\%) \\
\hline & Localized: 2(8\%) \\
\hline
\end{tabular}

Table-III. Symptoms

\begin{tabular}{|l|l|}
\hline \multirow{2}{*}{ Site of perforation } & Terminal ileum \\
\hline \multirow{2}{*}{$\begin{array}{l}\text { Dumber of perforations } \\
\text { junction in centimeter }\end{array}$} & Single: $23(92 \%)$ \\
\cline { 2 - 2 } & Multiple: $2(8 \%)$ \\
\hline Mean \pm SD:41.32 \pm 25.6 \\
\hline $\begin{array}{l}\text { Enlarge mesenteric lymph } \\
\text { nodes }\end{array}$ & $2(8 \%)$ \\
\hline Mode: 30 \\
\hline Procedure Performed
\end{tabular}

Table-IV. Operative findings and procedure performed

\begin{tabular}{|c|l|c|}
\hline 1 & Wound infection & $17(68 \%)$ \\
\hline 2 & Chest infection & $5(20 \%)$ \\
\hline 3 & Burst abdomen & $5(20 \%)$ \\
\hline 4 & Wound dehiscence & $2(8 \%)$ \\
\hline 5 & Skin excoriation & $2(8 \%)$ \\
\hline 6 & Death & $2(8 \%)$ \\
\hline 7 & Incisional hernia & $1(4 \%)$ \\
\hline 8 & Stoma retraction & $1(4 \%)$ \\
\hline 9 & Stoma prolapsed & $1(4 \%)$ \\
\hline & Table-V. Morbidities and mortalities \\
\hline
\end{tabular}

\section{DISCUSSION}

This young male predominance study was similarly comparable with the study conducted by Sumer A. and Sheshe AA., ${ }^{5,9}$ Our hospital is a tertiary care center and patients came from all over the province of Sindh. They are treated initially at primary or secondary health care centers and present to us after a delay with clinical presentation of peritonitis. This corresponds with the study carried out by Ugochukwu Al, in which more than half of the patients presented after 24 hours. ${ }^{6}$ This late stage is associated with septic shock and later on multi organ failure, which is has high morbidity and mortality rate. Our study showed that three patients presented in septic shock, out of which two letter on expired in postoperative period because of sepsis and multi organ failure. This was despite vagarious preoperative resuscitation and postoperative ventilator intensive care facility. This outcome is similarly comparable with Chaudhary $\mathrm{P}^{4}$ Symptoms of fever, abdominal pain, vomiting and signs of peritonitis in this study were also noted in other studies. ${ }^{7,10,8}$ The common second week presentation of typhoid ileal perforation of our study were also showed in other studies. ${ }^{11,12}$ This difference of earlier appearance of peritonitis in developing from developed countries seems to be because of decrease immunity, enormous disease burden along with virulent difference leading to increase ileal bacterial load with repeated infection causes Peyer's patches hypersensitivity. ${ }^{13,14}$ All patients were diagnosed as generalized peritonitis with only two patients in which clinical diagnosis of localized peritonitis were made which was similar to Ugochukwu Al. ${ }^{6}$ On exploration of abdomen large amount of purulent fluid was aspirated from the abdominal 
cavity, whereas only two patient had minimal purulent fluid, which was in contrast to the study conducted by Ansari AG, noted more than half of patient with minimal peritoneal contamination. ${ }^{8}$ Single perforation at terminal ileum was common also noted in other studies. ${ }^{6,15}$ However, Bhamre $\mathrm{S}$, noted that around half of the patients had two and more perforations. ${ }^{1}$ Whereas, the median distance of perforation from ileocecal junction of our study was slightly higher from the study conducted by Sheshe AA. Surgery remains the back bone of treatment in typhoid ileal perforation. However, small intestine in typhoid perforation is edematous, when making an anastomosis or repair sutures get cut through. So, it is better not to do it, moreover other risk factors are common in these patients like late presentation of generalized peritonitis leading to dehydrated and in electrolyte imbalance, sepsis and multi organ failure. ${ }^{16}$ In our study the most common procedure performed was loop ileostomy with good outcome. Primary closure of perforation with good surgical outcome noted by Bhamre S, Nema AA and Aliyu S. 1,7,8 Whereas, surgical procedures result of Ugochukwu Al, were nearly the same as our study but with more cases of primary closure as compare to our study. ${ }^{11}$ However, Chaudhary $P$, showed that resection and anastomosis was the preferred surgical approached. ${ }^{4} \mathrm{~A}$ case study of 15 typhoid ileal perforations in which bowel resection and ileotransverse anastomosis was made, eliminates all the disease ileum. ${ }^{17}$ Postoperative complications and mortality (death) with some minor difference were similar to other studies. ${ }^{1,7}$ Another study noted near similar post-operative surgical site infection but high mortality ${ }^{15}$ Study observed regular follow up in all patient for reversal of stoma group with 2 patients lost to follow up in after reversal group. This is in similarity with the study conducted by Bhamre S. ${ }^{1}$

\section{CONCLUSION}

Amongst the various surgical options, opted for patients presenting with peritonitis, following typhoid perforation loop ileostomy was observed to have better in relation to patient outcome. However, it appears that delayed presentation of patients suffering from typhoid perforation to health care facility have a significant effect on surgical outcome. So, principal importance is to be given on early clinical diagnosis of peritonitis and timely surgical intervention.

Copyright $@ 15$ Mar, 2019.

\section{REFERENCES}

1. Bhamre S, Chandak SS. A clinical profile of typhoid perforation of bowel in a tertiary care centre. MVP Journal of Medical Sciences, Vol 3(2), 83-91, JulyDecember 2016.

2. Brusch JL, Bronze MS, Typhoid Fever. Aug 19, 2019. https://emedicine.medscape.com/article/231135overview.

3. Contini S. Typhoid intestinal perforation in developing countries: Still unavoidable deaths? World J Gastroenterol. 2017 Mar 21; 23(11): 1925-31.

4. Chaudhary P, Kumar R, Munjewar $C$, Bhadana $U$, et al. Typhoid ileal perforation: A 13-year experience. Healthcare in Low-resource Settings 2015; 3:4677.

5. Sumer A, Kemik O, Dulger AC, Olmez A, Hasirci I, Kişli $E$, et al. Outcome of surgical treatment of intestinal perforation in typhoid fever. World $\mathrm{J}$ Gastroenterol. 2010 Sep 7; 16(33): 4164-4168. Published online 2010 Sep 7.

6. Ugochukwu Al, Amu OC, Nzegwu MA. Ileal perforation due to typhoid fever - Review of operative management and outcome in an urban centre in Nigeria. International Journal of Surgery 11(2013) 218222.

7. Nema AA, Darshan JR. A study of surgical approach to typhoid ileal perforation at a tertiary care hospital of South Gujarat, India. Int Surg J. 2018 May; 5(5):17581762.

8. Ansari AG, Naqvi SQH, Ghumro AA, Jamali AH, Talpur AA. Management of Typhoid Ileal Perforation: A Surgical Experience of $\mathbf{4 4}$ Cases. Gomal Journal of Medical Sciences January-June 2009, Vol. 7, No. 1.

9. Sheshe AA, Anyanwu LJC, Mohammad AM, Muhammad $A B$, Obaro SK. Typhoid intestinal perforation: Analysis of the outcome of surgical treatment in Kano, Nigeria. Arch Med Health Sci 2018; 6:59-63.

10. Poornima R, Venkatesh KL, Goutham MV, Nirmala, Hassan NN. Clinicopathological study of lleal perforation: study in tertiary center. Int Surg J. 2017 Feb; 4(2):543-549. 
11. Ugochukwu Al, Amub OC, Nzegwu MA. Ileal perforation due to typhoid fever - review of operative management and outcome in an urban centre in Nigeria. International Journal of Surgery. 2013; 11:21822.

12. Edino ST, Yakubu AA, Mohammed AZ, Abubakar IS. Prognostic factors in typhoid ileal perforation, a prospective study of $\mathbf{5 3}$ cases. J Natl Med Assoc. 2007; 99:1042-5.

13. Chalya PL, Mabula JB, Koy M, Kataraihya JB, Jaka $H$, Mshana SE. Typhoid intestinal perforations at a University teaching hospital in Northwestern Tanzania: A surgical experience of 104 cases in a resource-limited setting. World J Emerg Surg. 2012; $7: 4$.

14. Atamanalp SS, Aydinli B, Ozturk G, Oren D, Basoglu M, Yildirgan MI. Typhoid intestinal perforations: Twentysix-year experience. World J Surg. 2007; 31:1883-8.
15. Aliyu S, Babayo UD, Tahir MB, Zarami AB, Ibrahim AG, Madziga AG. Typhoid Perforation: Presentation and Management Outcome North-Eastern Nigeria. J Gastrointest Dig Syst. 2017;7(526):2.

16. Grema BA, Aliyu I, Michael GC, Musa A, Fikin AG, Abubakar BM, Olusegun S. Typhoid ileal perforation in a semi-urban tertiary health institution in northeastern Nigeria. South African Family Practice. 2018 Sep 3;60(5):168-73.

17. Momo Kadia B, Aroke D, Hongieh Abanda M, Njim T, Akem Dimala C. Bowel resection and ileotransverse anastomosis as preferred therapy for 15 typhoid ileal perforations and severe peritoneal contamination in a very elderly patient. Case reports in surgery. 2017;2017.

\begin{tabular}{|c|l|l|}
\hline \multicolumn{3}{|c}{ AUTHORSHIP AND CONTRIBUTION DECLARATION } \\
\hline Sr. \# & \multicolumn{1}{|c|}{ Author-s Full Name } & \multicolumn{1}{|c|}{ Contribution to the paper } \\
\hline 1 & Paras Mahesh & Primary author+Data collection. \\
\hline 2 & Syed Ahmad Sultan Ali & Co-author+Data analysis. \\
\hline 3 & Zainab Abdullah Kaludi & $\begin{array}{l}\text { Co-author+Data collection. } \\
\text { Critical review and finalizing }\end{array}$ \\
\hline 4 & Foad Ali Moosa & \begin{tabular}{l} 
manuscript. \\
\hline
\end{tabular}
\end{tabular}

